\title{
Qualidade microbiologica da carne de frango irradiada em embalagem convencional e a vácuo
}

[Microbiological evaluation of chicken breast meat irradiated in conventional and vacuum package]

\author{
A.L. Oliveira ${ }^{1}$, M.T. Pereira ${ }^{2}$, P.H.S. Bueno ${ }^{1}$, R.B.P. Oliveira ${ }^{3}$, \\ F.C. Pinto ${ }^{2}$, R.F. Correia ${ }^{2}$, M.M. Machado ${ }^{1}$ \\ ${ }^{1}$ Escola de Veterinária - UFMG \\ Caixa Postal 567 \\ 30123-970 - Belo Horizonte, MG \\ ${ }^{2}$ Centro de Desenvolvimento da Tecnologia Nuclear - UFMG - Belo Horizonte, MG \\ ${ }^{3}$ Centro Universitário - UNIBH - Belo Horizonte, MG
}

\begin{abstract}
RESUMO
Foram avaliados os efeitos da radiação gama nas doses de 1,5 e 3,0kGy, em peitos de frango embalados em embalagem convencional e a vácuo. As amostras embaladas foram submetidas à irradiação e estocadas sob refrigeração $\left(4^{\circ} \mathrm{C}\right)$ por 30 dias. A radiação mostrou-se eficiente na redução de mesófilos aeróbios estritos e facultativos viáveis, coliformes totais e termotolerantes, com destaque para Salmonella spp. Os bolores e leveduras mostraram-se bastante resistentes à radiação. Os resultados sugerem que a dose de 3,0kGy pode ser utilizada no controle da microbiota do peito de frango armazenado sob refrigeração, sendo uma alternativa para o aumento da vida de prateleira por até 10 dias, ao garantir a segurança do consumidor pela eliminação de possíveis patógenos.
\end{abstract}

Palavras-chave: peito de frango, radiação gama, irradiação, microbiologia, vida de prateleira

\begin{abstract}
The effects of gamma radiation doses of 1.5 and 3.0kGy on chicken breasts packed under conventional or vacuum atmosphere were evaluated. The packed samples were subjected to irradiation and stored under refrigeration $\left(4^{\circ} \mathrm{C}\right)$ for 30 days. The radiation was efficient in reducing strict and facultative aerobic mesophiles, total and fecal coliforms, and mainly Salmonella spp. The molds and yeasts were very resistant to radiation. The results suggest that gamma radiation at 3.0kGy can be used to control the microbiota in chicken breast stored under refrigeration, as an alternative to extend the shelf-life for more than ten days and ensure the food safety by eliminating potential pathogens.
\end{abstract}

Keywords: broiler breast, gamma radiation, irradiation, microbiology, shelf-life

\section{INTRODUÇÃO}

A carne de frango desempenha um papel importante na alimentação da população brasileira, devido ao seu preço baixo no comércio associado ao seu alto valor nutricional. Como produto de exportação, tem importância econômica para a geração de divisas para o país. Em 2006, foram exportados 2,7 milhões de toneladas de carne de frango com receita de 3,2 milhões de dólares, segundo a ABEF (Relatório..., 2006).

A carne de frango pode representar risco à saúde pública, por ser veículo frequente de transmissão de patógenos. Em alguns países, a carne de frango é considerada como umas das principais fontes de bactérias causadoras de enterites (Nascimento et al., 1996; Mead et al., 1999) e importante veiculadora de Salmonella spp. Além de Salmonella spp., a carne de frango pode veicular diversas bactérias patogênicas, destacando-se Campylobacter spp., Listeria spp., Escherichia coli O157:H7, Shigella spp. e Yersinia spp. Portanto, a garantia da segurança higiênico-sanitária da carne de frango, na cadeia produtiva de alimentos, representa uma importante ferramenta no controle e na prevenção das doenças de transmissão alimentar.

Recebido em 5 de fevereiro de 2009

Aceito em 8 de outubro de 2009

E-mail: afonso@vet.ufmg.br

Apoio: FAPEMIG 
A radiação gama é produzida por certos radioisótopos como, por exemplo, cobalto ${ }^{60} \mathrm{ou}$ césio $^{137}$, sendo uma radiação eletromagnética do tipo ionizante. Esse tipo de radiação tem maior potencial de utilização em produtos cárneos, devido à sua alta penetrabilidade e discreto aumento da temperatura do produto (Satin, 1996) A radiação gama age de duas maneiras sobre os microrganismos: uma produzindo radicais livres oxidativos que promovem danos às membranas celulares e outra provendo a quebra do ácido desoxirribonucleico, causando a paralisação do crescimento de microrganismos (Hackwood, 1991). A radiação também pode ser usada em combinação com outras técnicas, como a utilização de embalagens, contribuindo para maior estabilidade química e microbiológica do produto ou menor formação de compostos indesejáveis.

No Brasil, a legislação (Resolução..., 2001b) permite a irradiação de alimentos desde que a dose mínima absorvida seja suficiente para alcançar a finalidade pretendida e que a dose máxima absorvida seja inferior àquela que comprometeria as propriedades funcionais e os atributos sensoriais do alimento. $\mathrm{O}$ uso da radiação já é aprovado em 37 países para conservação de produtos alimentícios, reforçando a ideia de que, quando bem aplicado, o processo é seguro. De acordo com o Food and Drug Administration (FDA), a utilização de energia ionizante em alimentos representa um processo eficaz, e é aprovada pela Organização Mundial da Saúde, pela Associação Médica Americana e pelo Codex Alimentarius. Dessa maneira, a aplicação da radiação gama em alimentos mostra-se segura, sendo a carne de aves um dos produtos com grande potencial para o seu uso no Brasil (Pereira, 2004). O objetivo deste trabalho foi estudar o efeito de duas doses de irradiação, 1,5 e 3,0kGy, em dois tipos de embalagem, a vácuo e convencional, sobre as características microbiológicas de peito de frango avaliadas segundo a legislação vigente no país (Instrução..., 2003)

\section{MATERIAL E MÉTODOS}

As amostras de peito de frango, músculo peitoral torácico, foram adquiridas em abatedouro sob Inspeção Federal, na quantidade de $40 \mathrm{~kg}$, in natura, sem pele e sem ossos. As amostras foram acondicionadas em caixas de isopor contendo gelo em escamas, embaladas em caixas de papelão, revestidas por filme plástico, e encaminhadas imediatamente ao laboratório, para distribuição segundo os tratamentos e preparação para o processo de irradiação.

Utilizando-se de monoblocos, facas e tábuas de cortes previamente sanitizados com água hiperclorada e enxaguados com água destilada, os peitos foram divididos em dois meio-peitos, tendo como referência a calha do externo. O peso médio desses cortes foi de $158 \mathrm{~g}$. Esses meiopeitos foram colocados em monoblocos de polietileno de alta densidade onde foi realizado o processo de homogeneização da contaminação inicial, sendo cada peito esfregado sobre os demais.

Um grupo de 96 amostras foi colocado em embalagem de atmosfera convencional, com fechamento hermético marca Ziploc ${ }^{\circledR}{ }^{1}$, aprovada pelo FDA (Packaging..., 2008) para irradiação de alimentos, medindo $17,8 \mathrm{~cm} \times 20,3 \mathrm{~cm}$. As demais 96 amostras foram embaladas a vácuo utilizando embalagens plásticas de polietileno, medindo $13 \mathrm{~cm} \times 22 \mathrm{~cm}$, também aprovados pelo FDA (Packaging..., 2008) para irradiação de alimentos. $\mathrm{O}$ ar residual foi mecanicamente retirado, e as embalagens foram seladas pelo calor, utilizandose uma seladora MINIVAC CV $18^{2}$.

As 96 amostras acondicionadas em embalagem de atmosfera convencional foram distribuídas em três grupos de 32 amostras. O primeiro grupo foi utilizado como controle $\left(\mathrm{C}_{\text {convencional }}\right)$ e mantido sob refrigeração, e os outros dois foram enviados ao Laboratório de Irradiação Gama (LIG), localizado no Centro de Desenvolvimento de Tecnologia Nuclear, para que as amostras fossem irradiadas. O mesmo aconteceu com as amostras embaladas a vácuo, sendo um grupo de amostras mantido sob refrigeração $\left(\mathrm{C}_{\text {vácuo }}\right)$ e os demais destinados à irradiação.

Todas as amostras destinadas a irradiação, embaladas e identificadas foram acondicionadas em caixas de isopor lacradas, contendo gelo reciclável, com o objetivo de manter a temperatura estável $\left(4^{\circ} \mathrm{C}\right) . \mathrm{Na} \mathrm{LIG}$, receberam doses de $1,5 \mathrm{kGy}\left(\mathrm{T}_{1,5 \text { convencional }}\right.$ e $\left.\mathrm{T}_{1,5 \text { vacuo }}\right)$ e $3,0 \mathrm{kGy}\left(\mathrm{T}_{3,0 \text { convencional }}\right.$ e $\left.\mathrm{T}_{1,5 \text { vacuo }}\right)$. Durante todo o

\footnotetext{
${ }^{1}$ Johnson SC. Ltda, Rio de Janeiro, Brasil.
}

${ }^{2}$ Selovac Ind.Com. Ltda, São Paulo, Brasil. 
processo de irradiação, a temperatura foi controlada. Foi utilizado um irradiador piloto, de pequeno porte, modelo Gamabeam $127^{3}$, classificado como um irradiador panorâmico de fonte de estocagem a seco, que utiliza uma fonte de Cobalto ${ }^{60}$.

As amostras foram colocadas a uma distância da fonte que resultou na taxa de dose de $1,0 \mathrm{kGy} / \mathrm{h}$, em mesas rotatórias, o que permitiu uniformidade de dose em todas as amostras. Os grupos $\mathrm{T}_{1,5 \text { convencional }}$ e $\mathrm{T}_{1,5 \text { vácuo }}$ permaneceram durante 90 minutos no irradiador, enquanto os grupos $\mathrm{T}_{3,0 \text { convencional }}$ e $\mathrm{T}_{3,0 \text { vácuo }}$ tiveram as amostras irradiadas por 180 minutos.

Após serem irradiadas, as amostras foram encaminhadas ao Laboratório de Ciência e Tecnologia de Carnes da Escola de Veterinária da UFMG, onde foram estocadas em câmara de incubação tipo $\mathrm{BOD}$, modelo $347 \mathrm{CD}^{4}$ à temperatura de $4^{\circ} \mathrm{C} \pm 2^{\circ} \mathrm{C}$. A temperatura em cada uma das câmaras foi registrada diariamente por termômetro digital, com os sensores sendo colocados em duas posições (primeira e última prateleira), sendo que a variação de temperatura, em nenhum momento, ultrapassou os $2^{\circ} \mathrm{C}$. Semanalmente, a temperatura foi aferida com termômetros calibrados de bulbo úmido. A disposição das amostras foi feita de maneira que $\mathrm{o}$ ar frio atingisse por igual todas as amostras, e a retirada para análise foi realizada aleatoriamente entre prateleiras e câmaras.

As análises microbiológicas foram realizadas, sendo utilizadas como indicadores de qualidade microbiológica as determinações de: contagem padrão de mesófilos aeróbios estritos e facultativos viáveis, contagem de bolores e leveduras, número mais provável de coliformes totais e coliformes termotolerantes e determinação de presença de Salmonella spp. $\mathrm{Na}$ caracterização inicial, foram analisadas quatro amostras de cada um dos seis tratamentos, totalizando 24 amostras. Durante a estocagem refrigerada aos $5,10,15$ e 30 dias, também foram analisadas para cada tratamento quatro amostras, totalizando 96 amostras. O experimento foi suspenso aos 30 dias, quando as amostras se apresentaram com alteração de odor, sendo as demais amostras descartadas. As análises microbiológicas foram realizadas conforme metodologia recomendada pela da Instrução Normativa $N^{o} 62$ (Instrução..., 2003) que normaliza os métodos analíticos oficiais para análises microbiológicas para controle de produtos de origem animal e água.

Os resultados obtidos foram submetidos à análise de variância para identificar tratamentos com respostas significativas. Os dados coletados (valores absolutos) foram transformados para valores logarítmicos das contagens. Para a comparação de média, empregou-se o teste Tukey e, para análise dos dados, usou-se o programa Minitab ${ }^{\circledR}$, versão 14.0.

\section{RESULTADOS E DISCUSSÃO}

Os dados da Tab. 1 representam a média das contagens obtidas na caracterização microbiológica inicial das amostras. Essa caracterização foi realizada imediatamente após a irradiação das amostras, ou seja, no dia 0 de experimento.

Em todas as amostras não irradiadas (controle), tanto em embalagem convencional quanto a vácuo, ocorreu Salmonella spp. em $25 \mathrm{~g}$, fato que as excluem dos padrões mínimos para registro e fiscalização de produtos alimentícios, estipulados pela legislação (Resolução..., 2001a). Salmonella é causadora de graves toxinfecções alimentares, e sua presença nas amostras-controle demonstra a necessidade de medidas de controle e garantia da segurança alimentar. Cabe destacar que, durante o processo de preparo das amostras para irradiação, foi identificado, visualmente, matéria orgânica, possivelmente de origem fecal, presente na superfície do peito de frangos. Assim, pode-se supor que a contaminação das amostras por esse patógeno tenha sido causada pelo rompimento do trato gastrintestinal ou do inglúvio durante a etapa de evisceração das aves (Hargis et al., 1995). Não foi evidenciada a presença de Salmonella spp. em $25 \mathrm{~g}$ nas amostras submetidas à irradiação, indicando que doses de 1,5kGy, tanto em embalagens a vácuo quanto na convencional, foram suficientes para eliminar a Salmonella spp. das amostras de peito de frango.

${ }^{3}$ MDS Nordion, Kanata, Ontario, Canadá.

${ }^{4}$ FANEM, São Paulo, Brasil. 
Tabela 1. Caracterização microbiológica inicial de amostras de peito de frango armazenadas sob refrigeração $\left(4^{\circ} \mathrm{C}\right)$, embaladas em embalagem convencional ou a vácuo, e submetidas à irradiação com taxa de dose de $1,5 \mathrm{kGy}$ ou $3,0 \mathrm{kGy}$

\begin{tabular}{lccccc}
\hline Tratamento & $\begin{array}{c}\text { Mesófilos } \\
\text { aeróbios } \\
(\text { Log UFC/g) }\end{array}$ & $\begin{array}{c}\text { Coliformes } \\
\text { totais } \\
(\text { Log NMP/g) }\end{array}$ & $\begin{array}{c}\text { Coliformes } \\
\text { termotolerantes } \\
(\text { Log NMP/g) }\end{array}$ & $\begin{array}{c}\text { Bolores e } \\
\text { leveduras } \\
(\text { Log UFC/g) })^{1}\end{array}$ & $\begin{array}{c}\text { Salmonella } \\
\text { spp. }^{2,3}\end{array}$ \\
\hline Controle-convencional & $3,0 \mathrm{a} \pm 0,01$ & $2,9 \mathrm{a} \pm 0,3$ & $2,9 \mathrm{a} \pm 0,3$ & $4,1 \mathrm{a} \pm 0,2$ & Presente \\
Controle-vácuo & $2,8 \mathrm{a} \pm 0,1$ & $2,5 \mathrm{a} \pm 0,2$ & $2,1 \mathrm{a} \pm 0,3$ & $2,7 \mathrm{ab} \pm 0,3$ & Presente \\
$1,5 \mathrm{kGy}$-convencional & $<1,0 * \mathrm{~b}$ & $0,3 * \mathrm{~b} \pm 0,4$ & $0,4 * \mathrm{a} \pm 0,6$ & $2,5 \mathrm{~b} \pm 1,1$ & Ausente \\
1,5kGy-vácuo & $<1,0 * \mathrm{~b}$ & $<0,5 * \mathrm{~b}$ & $<0,5 * \mathrm{a}$ & $1,1 \mathrm{ab} \pm 1,5$ & Ausente \\
3,0kGy-convencional & $<1,0 * \mathrm{~b}$ & $<0,5 * \mathrm{~b}$ & $<0,5 * \mathrm{a}$ & $1,0 \mathrm{~b} \pm 1,4$ & Ausente \\
3,0kGy-vácuo & $<1,0 * \mathrm{~b}$ & $<0,5 * \mathrm{~b}$ & $<0,5 * \mathrm{a}$ & $<1,0 * \mathrm{~b}$ & Ausente \\
\hline
\end{tabular}

*Valores estimados segundo Instrução... (2003). A análise estatística foi realizada utilizando os valores absolutos encontrados.

Letras diferentes na mesma coluna indicam valores que diferem entre si $(\mathrm{P}<0,05)$ pelo teste Tukey.

${ }^{1}$ Média de quatro amostras.

${ }^{2}$ Média de duas amostras.

${ }^{3}$ Presença em $25 \mathrm{~g}$ de amostra.

Thayer et al. (1992) descreveram a eliminação de Salmonella Typhimurium inoculadas em carnes de aves, ao utilizarem doses de 2,7kGy, e Clavero et al. (1994) obtiveram resultados satisfatórios na eliminação de Salmonella spp., ao empregarem doses menores que 3,0kGy. Dickson (1995) propôs doses entre 1,5-3,0kGy para a eliminação de Salmonella spp. Lescano et al. (1991) não encontraram Salmonella spp. em carne de frango irradiada com $2,5 \mathrm{kGy}$ e Santos et al. (2003) sugeriram doses mínimas de 3,8kGy para garantia da segurança alimentar quanto à presença de Salmonella spp.

Mesmo em doses inferiores àquelas propostas, a irradiação pode contribuir com o controle da Salmonella spp. Estudos demonstraram que a irradiação pode causar aumento da sensibilidade de microrganismos ao calor (Kim e Thayer, 1996). Portanto, a irradiação de carne crua pode aumentar a segurança alimentar, aumentando a sensibilidade da Salmonella spp. e de outros patógenos aos processos de preparo culinário tradicional.

A maioria das bactérias encontradas em aves vivas são mesófilas aeróbias, porém, esse tipo de bactéria encontra dificuldades para se desenvolver em temperaturas de refrigeração. Altas contagens desses microrganismos na carne de frango têm sido associadas a condições higiênico-sanitárias precárias durante o abate ou processamento das carcaças.

Na Fig. 1, observa-se que as contagens iniciais de microrganismos mesófilos aeróbios estritos e facultativos viáveis das amostras-controle, em embalagem convencional e a vácuo, foram de 3,0 e $2,8 \mathrm{Log} \mathrm{UFC} / \mathrm{g}$, respectivamente. Esses números são bastante elevados, considerando que a análise foi realizada no dia do abate e processamento.

A irradiação reduziu a contagem desses microrganismos em, aproximadamente, três ciclos logarítmicos, resultado condizente com o encontrado por Miyagusku et al. (2003). O desenvolvimento das bactérias mesófilas aeróbias e facultativas foi intenso nas amostras controle, atingindo $6,0 \mathrm{Log} \mathrm{UFC} / \mathrm{g}$ antes do quinto dia de estocagem refrigerada (Fig. 1). Para as amostras irradiadas com $1,5 \mathrm{kGy}$, tanto em embalagem convencional quanto a vácuo, os valores acima de 6,0 Log UFC/g somente foram observados após 10 dias de estocagem refrigerada. $\mathrm{O}$ grupo que recebeu a maior dose de radiação $(3,0 \mathrm{kGy})$ somente ultrapassou $6,0 \mathrm{Log}$ UFC/g após 30 dias de estocagem refrigerada, para ambas as embalagens. Isso indica que o aumento da dose de irradiação gama aplicada sobre filés de peito de frango tem significativa influência nas contagens de mesófilos aeróbios estritos e facultativos viáveis, resultado similar aos relatados por Miyagusku et al. (2003) e Kim et al. (2006). Abu-Tarboush et al. (1997), ao avaliarem frangos submetidos a várias doses de irradiação, observaram que na dose de 2,5 kGy ocorreu prolongamento da vida de prateleira por até 12 dias, e que doses acima de 2,5 kGy resultaram em pouco ou nenhum benefício adicional na redução da contagem bacteriana. 


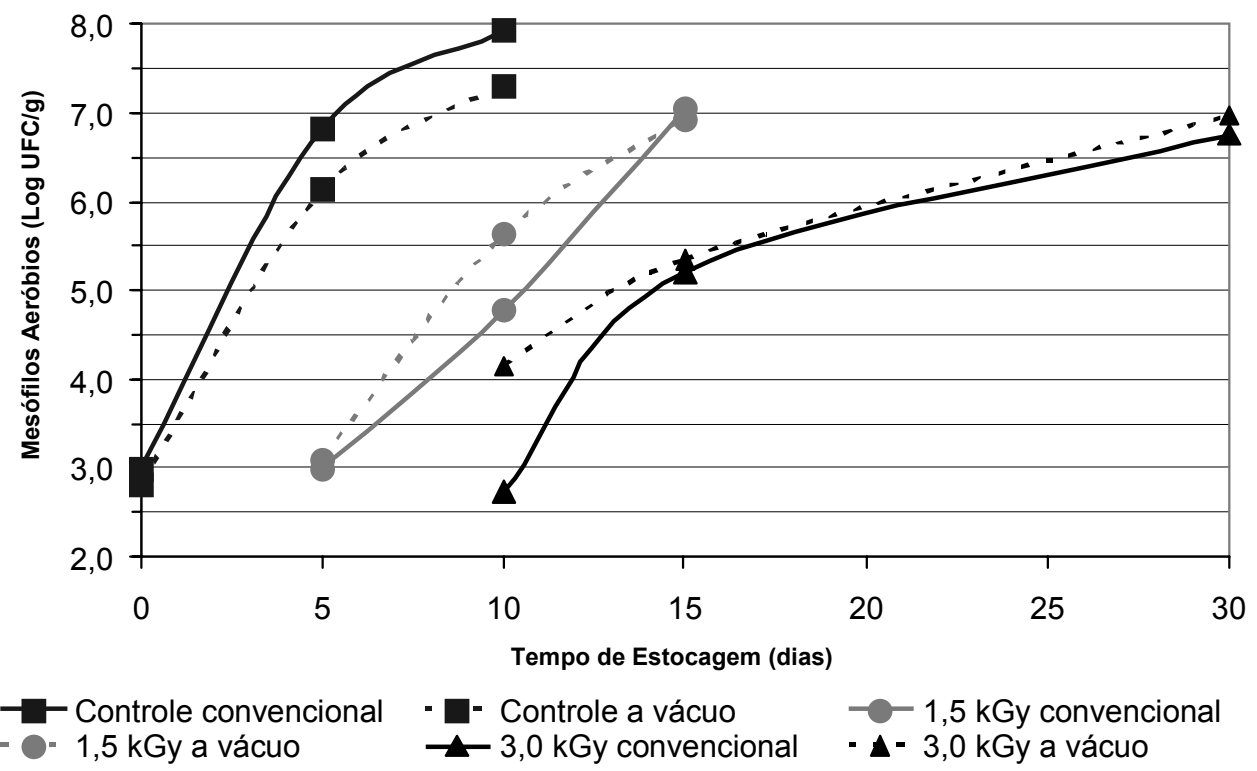

Figura 1. Crescimento de microrganismos mesófilos aeróbios estritos e facultativos viáveis em amostras de peito de frango armazenadas sob refrigeração $\left(4^{\circ} \mathrm{C}\right)$, embaladas em embalagem convencional ou a vácuo, e submetidas à irradiação com taxa de dose de 1,5kGy ou 3,0kGy.

Não houve diferença significativa entre as contagens de microrganismos mesófilos aeróbios e facultativos viáveis entre os dois tipos de embalagens utilizadas.

Em relação à contagem de coliformes das amostras controle, na primeira análise, os valores observados indicaram cargas relativamente elevadas de coliformes totais e termotolerantes (Tab. 2 e 3), valores próximos aos observados por Miyagusku et al. (2003).

A irradiação reduziu a população de coliformes, mantendo as contagens de coliformes totais inferiores a $1,0 \log \mathrm{NMP} / \mathrm{g}$ durante todo $\mathrm{o}$ período de experimento. Não foram observadas diferenças $(\mathrm{P}>0,05)$ entre os tratamentos para $\mathrm{o}$ parâmetro de coliformes termotolerantes. Provavelmente esse comportamento foi causado pelo valor elevado do desvio-padrão observado nas amostras. Esses resultados sugerem que se os grupos amostrais fossem maiores, ou se fossem utilizados testes estatísticos menos rigorosos, poderia ser observada diferença estatística entre os tratamentos, indicando o efeito da dose de radiação sobre o grupo dos coliformes termotolerantes.
Não se observou efeito da dose de irradiação utilizada em relação às embalagens (Tab. 3), embora os valores absolutos tenham sido mais elevados para a contagem das amostras em embalagens a vácuo. A maior concentração de microrganismos na embalagem a vácuo pode ser parcialmente explicada pela ausência de oxigênio durante o processo de irradiação, causando a menor formação de radicais livres oxidativos, principalmente hidroxil, que age sobre as células bacterianas, injuriando-as ou inativando-as. $\mathrm{O}$ padrão de maior concentração de microrganismos nas embalagens a vácuo também aconteceu nas contagens de mesófilos estritos e facultativos viáveis, porém com menor intensidade. A eliminação de coliformes totais no tratamento embalado a vácuo e tratado com 3,0kGy foi atribuída ao maior dano ao DNA ocasionado pela dose mais alta de radiação. Seydim et al. (2006) não encontraram diferenças entre a embalagem a vácuo e a embalagem convencional para número de coliformes totais durante a vida de prateleira de carne de avestruz não irradiada. 
Tabela 2. Número mais provável de coliformes totais (Log NMP/g) em amostras de peito de frango armazenadas sob refrigeração $\left(4^{\circ} \mathrm{C}\right)$, embaladas em embalagem convencional ou a vácuo, e submetidas à irradiação com taxa de dose de $1,5 \mathrm{kGy}$ ou $3,0 \mathrm{kGy}$

\begin{tabular}{ccccccc}
\hline \multirow{2}{*}{ Tratamento } & & \multicolumn{5}{c}{ Período de estocagem $4^{\circ} \mathrm{C}$ (dias) } \\
\cline { 3 - 7 } & & 0 & 5 & 10 & 15 & 30 \\
\hline \multirow{2}{*}{ Controle } & Conv. & $2,9 \mathrm{a} \pm 0,3$ & $3,9 \mathrm{a} \pm 0,5$ & $5,8 \mathrm{a} \pm 0,6$ & $\mathrm{NR} 1$ & $\mathrm{NR}^{1}$ \\
& Vácuo & $2,5 \mathrm{a} \pm 0,2$ & $3,9 \mathrm{a} \pm 0,5$ & $5,1 \mathrm{a} \pm 0,7$ & $\mathrm{NR} 1$ & $\mathrm{NR}^{1}$ \\
\multirow{2}{*}{$1,5 \mathrm{kGy}$} & Conv. & $0,3 \mathrm{~b} \pm 0,4$ & $<0,5^{*} \mathrm{~b}$ & $<0,5^{*} \mathrm{~b}$ & $<0,5^{*} \mathrm{a}$ & $\mathrm{NR}^{1}$ \\
& Vácuo & $1,0 \mathrm{~b} \pm 0,0$ & $0,8 \mathrm{~b} \pm 1,7$ & $0,4 \mathrm{~b} \pm 0,7$ & $0,4 \mathrm{~b} \pm 0,5$ & $\mathrm{NR}^{1}$ \\
\multirow{2}{*}{$3,0 \mathrm{kGy}$} & Conv. & $<0,5^{*} \mathrm{~b}$ & $<0,5^{*} \mathrm{~b}$ & $<0,5^{*} \mathrm{~b}$ & $<0,5^{*} \mathrm{ab}$ & $<0,5^{* \mathrm{a}}$ \\
& Vácuo & $<0,5^{*} \mathrm{~b}$ & $<0,5^{*} \mathrm{~b}$ & $0,6 \mathrm{~b} \pm 0,7$ & $<0,5^{*} \mathrm{ab}$ & $<0,5^{* \mathrm{a}}$ \\
\hline
\end{tabular}

*Valores obtidos pela técnica do número mais provável (Instrução..., 2003). A análise estatística foi realizada utilizando os valores absolutos encontrados.

${ }^{1}$ Não realizado (amostra descartada devido à deterioração).

Letras diferentes na mesma coluna indicam valores que diferem entre si $(\mathrm{P}<0,05)$ pelo teste Tukey.

Tabela 3. Número mais provável de coliformes termotolerantes (Log NMP/g) em amostras de peito de frango armazenadas sob refrigeração $\left(4^{\circ} \mathrm{C}\right)$, embaladas em embalagem convencional ou a vácuo, e submetidas à irradiação com taxa de dose de 1,5kGy ou 3,0kGy

\begin{tabular}{llccccc}
\hline \multirow{2}{*}{ Tratamento } & \multicolumn{5}{c}{ Período de estocagem $4^{\circ} \mathrm{C}$ (dias) } \\
\cline { 3 - 6 } & & 0 & 5 & 10 & 15 & 30 \\
\hline \multirow{2}{*}{ Controle } & Conv. & $2,9 \mathrm{a} \pm 0,3$ & $2,8 \mathrm{a} \pm 1,9$ & $3,5 \mathrm{a} \pm 2,3$ & $\mathrm{NR} 1$ & $\mathrm{NR} 1$ \\
& Vácuo & $2,1 \mathrm{a} \pm 0,2$ & $2,1 \mathrm{a} \pm 2,4$ & $2,4 \mathrm{ab} \pm 2,7$ & $\mathrm{NR} 1$ & $\mathrm{NR} 1$ \\
\multirow{3}{*}{$1,5 \mathrm{kGy}$} & Conv. & $0,4 \mathrm{a} \pm 0,6$ & $<0,5^{*} \mathrm{a}$ & $<0,5^{*} \mathrm{a}$ & $<0,5^{*} \mathrm{a}$ & $\mathrm{NR} 1$ \\
& Vácuo & $1,0 \mathrm{a} \pm 0,0$ & $1,0 \mathrm{a} \pm 2,0$ & $<0,5 * \mathrm{~b}$ & $0,4 \mathrm{a} \pm 0,5$ & $\mathrm{NR} 1$ \\
\multirow{2}{*}{$3,0 \mathrm{kGy}$} & Conv. & $<0,5^{*} \mathrm{a}$ & $<0,5^{*} \mathrm{a}$ & $<0,5^{*} \mathrm{~b}$ & $<0,5^{*} \mathrm{~b}$ & $<0,5^{*} \mathrm{a}$ \\
& Vácuo & $<0,5^{*} \mathrm{a}$ & $<0,5^{*} \mathrm{a}$ & $0,7 \mathrm{~b} \pm 0,8$ & $<0,5^{*} \mathrm{a}$ & $<0,5^{*} \mathrm{a}$ \\
\hline
\end{tabular}

*Valores obtidos pela técnica do número mais provável (Instrução..., 2003). A análise estatística foi realizada utilizando os valores absolutos encontrados.

${ }^{1}$ Não realizado (amostra descartada devido à deterioração).

Letras diferentes na mesma coluna indicam valores que diferem entre si $(\mathrm{P}<0,05)$ pelo teste Tukey.

$\mathrm{Na}$ caracterização microbiológica inicial, os valores das contagens de bolores e leveduras foram relativamente altos para carnes de frango. Essa contaminação pode ser resultado de procedimentos falhos de evisceração, com consequente rompimento de vísceras e contaminação da carne. Durante o processo de preparo das amostras, foi observado conteúdo de trato gastrintestinal, aparentemente não digerido, em alguns dos filés de peito, podendo significar que ocorreu o rompimento do inglúvio das aves durante a evisceração.

Os bolores e leveduras mostraram-se bastante resistentes à irradiação. A diminuição das contagens de bolores e leveduras, quando sujeitos à irradiação, foi menor que a dos outros microrganismos. Foi possível notar, também, que a estocagem refrigerada em embalagem a vácuo foi mais eficiente no controle de bolores e leveduras, causando redução média de 0,5 ciclos logarítmicos, quando comparada a amostras sujeitas à mesma dose de irradiação e embaladas em embalagem convencial (Fig. 2). Miyagusku et al. (2003) encontraram menor redução nas contagens de bolores e leveduras mesmo quando se aplicaram doses mais altas de irradiação (7,0kGy).

Apesar de citado na literatura (Josephson e Peterson, 1983; Yldrm et al., 2005), não foi encontrada evidência de que a maior complexidade da estrutura genômica dos bolores e leveduras teria aumentado sua sensibilidade à irradiação. Pelo contrário, esses microrganismos apresentaram a maior radiorresistência entre os analisados neste experimento. 


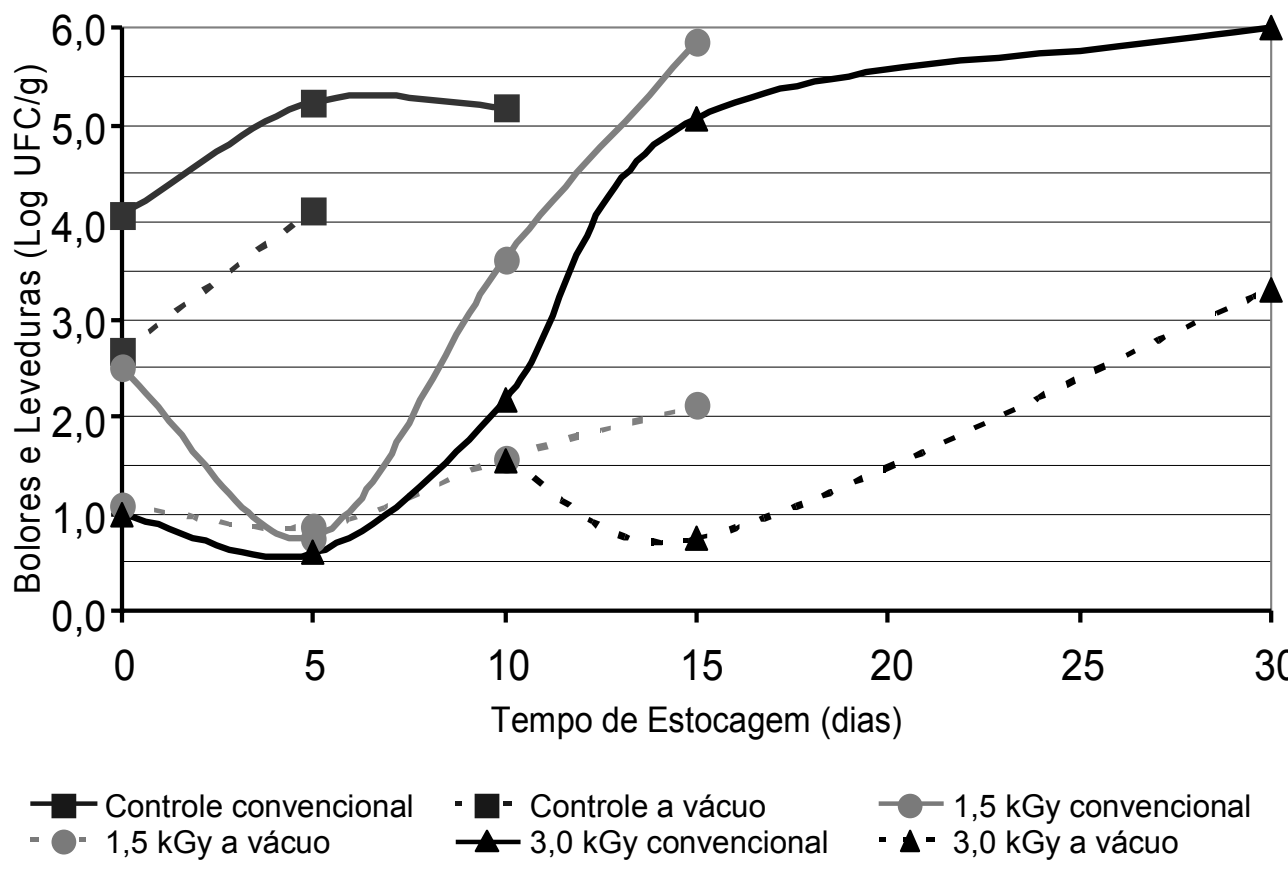

Figura 2. Crescimento de bolores e leveduras em amostras de peito de frango armazenadas sob refrigeração $\left(4^{\circ} \mathrm{C}\right)$, embaladas em embalagem convencional ou a vácuo, e submetidas a irradiação com taxa de dose de $1,5 \mathrm{kGy}$ ou $3,0 \mathrm{kGy}$

A maioria dos bolores e leveduras encontrados em alimentos é aeróbia (Jay, 2000). Isso explica o maior crescimento observado desse grupo de microrganismos nas amostras em embalagem convencional, pois, mesmo com a formação de radicais livres, peróxidos, e o consequente dano sobre as membranas celulares, a presença do oxigênio favorece o crescimento dos bolores e leveduras nas amostras acondicionadas em embalagem de atmosfera convencional.

Outro fator que pode ter influenciado na alta radiorresistência desses bolores e leveduras é a constituição de sua parede celular, com menor quantidade de ácidos graxos, portanto, menos sensível aos compostos oxidativos formados durante o processo de irradiação.

Foi observado maior crescimento de colônias típicas de leveduras quando comparado ao de colônias típicas de bolores. Isso pode ser explicado pela maior resistência, devido à complexidade celular do primeiro grupo à irradiação (Jay, 2000).

\section{CONCLUSÕES}

A radiação gama é eficiente na eliminação de Salmonella spp., no controle da população de microrganismos mesófilos aeróbios estritos e facultativos viáveis, coliformes totais e termotolerantes. A radiação gama é pouco eficiente no controle de bolores e leveduras em peito de frango armazenado sob refrigeração $\left(4^{\circ} \mathrm{C}\right)$, em embalagem convencional ou a vácuo. Doses de 3,0kGy podem ser utilizadas para ampliar a vida de prateleira de peito de frango armazenado sobre refrigeração $\left(4^{\circ} \mathrm{C}\right)$, em embalagem convencional ou a vácuo, alem de garantir ao consumidor mais segurança alimentar, por eliminar Salmonella spp. da carne de frango.

\section{AGRADECIMENTOS}

À Fundação de Amparo à Pesquisa do Estado de Minas Gerais (FAPEMIG), pelo financiamento do projeto de pesquisa (CVZ APQ-0672-5.0507). 


\section{REFERÊNCIAS BIBLIOGRÁFICAS}

ABU-TARBOUSH, H.M.; AL-KAHTANI, H.A.; ATIA, M. et al. Sensory and microbial quality of chicken as affected by irradiation and post irradiation storage at 4.0 degrees. Can. J. Food Prot., v.60, p.761$770,1997$.

CLAVERO, M.R.S.; MONK, J.D.; BEUCHAT, L.R. et al. Inactivation of Escherichia coli O157:H7, Salmonella and Campylobacter jejuni in raw ground beef by gamma irradiation. Appl. Environ. Microbiol., v.60, p.2069-2075, 1994.

DICKSON, J.S. Radurization - The pasteurization of foods by ionizing radiation. J. Food Prot., v.58, suppl., p.1-70, 1995.

HACKWOOD, S. An introduction to the irradiation processing foods. In: THORNE, S. Food irradiation. London: Elsevier Applied Science, 1991. p.1-18

HARGIS, B.M.; CALDWELL, D.J.; BREWER, R.L. et al. Evaluation of the chicken crop as a source of Salmonella contamination for broiler carcasses. Poult. Sci., v.74, p.1548-1552, 1995.

INSTRUÇÃO normativa 62, de 26 de agosto de 2003. Métodos analíticos oficiais para análises microbiológicas para o controle de produtos de origem animal e água [do Ministério da Agricultura Pecuária e Abastecimento]. Diário Oficial da União, Brasília, DF, 18 set. 2003. p.14-50.

JAY, J.M. Modern food microbiology. 6 ed. Gaithersburg, MD: Aspen Publishers, 2000. 637p.

JOSEPHSON, E.S.; PETERSON, M.S. Preservation of food by ionizing radiation. Boca Raton: CRC, 1983. $343 \mathrm{p}$.

KIM, A.Y.; THAYER, D.W. Mechanism by which gamma irradiation increases the sensitivity of Salmonella typhimurium ATCC 14028 to heat. Appl. Environ. Microbiol., v.62, p.1759-1763, 1996.

KIM, J.; LEE, J.; KIM, J. et al. Effect of gamma irradiation on Listeria ivanovii inoculated to iceberg lettuce stored at cold temperature. Food Control, v.17, p.397-401, 2006.

LESCANO, G.; NARVAIZ, P.; KAIRIYAMA, E. et al. Effect of chicken breast irradiation on microbiological, chemical and organoleptic quality. Lebensmittel Wiss. Technol., v.24, p.130-134, 1991.

MEAD, P.S.; SLUTSKER, L.; DIETZ, V. et al. Foodrelated illness and death in the United States. Emerg. Infect. Dis., v.5, p.607-625, 1999.
MIYAGUSKU, L.; CHEN, F.; LEITAO, M.F.D.F. et al. Microbiological, sensory and shelf-life evaluation of irradiated chicken breast meat. Cienc. Tecnol. Aliment., v.23, supl., p.7-16, 2003.

NASCIMENTO, V.P.; SANTOS, L.R.; CARDOSO, M.D.O. et al. Qualidade microbiológica de produtos avícolas. In: SIMPÓSIO GOIANO DE AVICULTURA, 2., 1996, Goiânia. Anais... Goiânia: Associação Goiana de Avicultura, UFG, 1996. p.13-17.

PACKAGING materials listed in 21 CFR 179.45 for use during irradiation of prepackaged foods. FDA. Center for Food Safety \& Applied Nutrition. Disponível em: http://www.cfsan.fda.gov/ dms/irrapack.html. Acesso em:12 jun. 2008.

PEREIRA, A.S.C. Irradiação em alimentos. Rev. Nac. Carne, n.324, p.53-62, 2004.

RELATÓRIO anual da Associação Brasileira dos Exportadores de Frango. São Paulo: Associação Brasileira dos Produtores e Exportadores de Frango, 2006. 30p.

RESOLUÇÃO RDC n ${ }^{\circ} 12$ de 02 de janeiro de 2001. Regulamento técnico sobre padrões microbiológicos para alimentos [do Ministério da Saúde]. Diário Oficial da União, Brasília, DF, 10 jan. 2001a. Seção 1.

RESOLUÇÃO RDC n 21 de 26 de janeiro de 2001. Regulamento técnico para a irradiação de alimentos [do Ministério da Saúde]. Diário Oficial da União, Brasília, DF, 29 jan. 2001b. Seção 1, p.35.

SANTOS, A.F.; VIZEU, D.M.; DESTRO, M.T. et al. Determinação da dose de radiação gama para reduzir a população de Salmonella spp. em carne de frango. Cienc. Tecnol. Aliment., v.23, p.200-205, 2003.

SATIN, M. Food irradiation: A guidebook. 2.ed. Lancaster, PA: Technomic, 1996. 211p.

SEYDIM, A.C.; ACTON, J.C.; HALL, M.A. et al. Effects of packaging atmospheres on shelf-life quality of ground ostrich meat. Meat Sci., v.73, p.503-510, 2006.

THAYER, D.W.; DICKERSON, C.Y.; RAO, D.R. et al. Destruction of Salmonella typhimurium on chicken wings by gamma radiation. J. Food Sci., v.57, p.586589, 1992.

YLDRM, I.; UZUNLU, S.; TOPUZ, A. Effect of gamma irradiation on some principle microbiological and chemical quality parameters of raw turkish meat ball. Food Control, v.16, p.363-367, 2005. 